\title{
Ensino de Inglês para Alunos com Transtorno de Déficit de Atenção e Hiperatividade
}

\author{
English Teaching to Students with Attention Deficit Hyperactivity Disorder
}

\author{
Ane Caroline dos Santos $;$ Fábio Henrique Rosa Senefonte \\ anniversidade Estadual do Norte do Paraná, Curso de Letras. PR. Brasil. \\ bUniversidade Estadual do Norte do Paraná. PR, Brasil. \\ E-mail: fabiosenefonte@uenp.edu.br
}

\begin{abstract}
Resumo
Tendo como pano de fundo o ensino de línguas para alunos com Transtorno de Déficit de Atenção e Hiperatividade (TDAH), esta pesquisa tem como objetivo geral investigar a realidade e as possibilidades em relação ao ensino de inglês para alunos TDAH no município de AndiráPR. Como objetivo específico, este estudo busca descrever e explicar estratégias/métodos na pedagogia de inglês para alunos com TDAH no município citado. Alinhadas aos objetivos, o estudo visa responder às seguintes perguntas de pesquisa: (a) Que desafios, se algum, os professores enfrentam ao ensinar inglês a alunos com TDAH no contexto investigado? (b) Que estratégias de ensino são empregadas para o ensino de inglês a alunos com TDAH? A literatura que embasa o estudo se situa no âmbito do ensino e aprendizagem de línguas para alunos com TDAH. Este estudo de caso, de natureza qualitativa, envolve dois participantes de duas escolas públicas no município supramencionado. O instrumento de geração de dados se constitui de observação de seis aulas, três em cada instituição, e uma entrevista semiestruturada, gravada em áudio. Os dados sinalizam uma falta de sistematização e dificuldades metodológicas para a pedagogia de língua inglesa. No entanto, a integração de alunos com TDAH pode trazer ganhos de ordem cognitiva e pragmática.
\end{abstract}

Palavras-chave: Ensino de Língua Inglesa. Perspectiva Inclusiva. TDAH.

\begin{abstract}
Having as background language teaching to students with Attention Deficit Hyperactivity Disorder (ADHD), this research primarily aims to investigate the reality and possibilities regarding English teaching to students with ADHD in Andirá-PR. Furthermore, it seeks to describe and explain strategies/ methods for English teaching to students with ADHD in the aforementioned town. Aligned with the aims, this study also endeavors to answer the following research questions: (a) What challenges, if any, do teachers face when they teach English to students with ADAH in the context investigated? (b) Which strategies/ methods are employed in English teaching to students with ADAH? The literature that supports this research includes the context of teaching-learning to students with ADHD. The case study, of qualitative nature, involves two participants of two public schools in the above-mentioned town. The data generation tools encompass observations of six classes, three in each institution and a semi-structured, audio-recorded interview. The findings bespeak a lack of systematization and methodological difficulties to English teaching. Nonetheless, the integration of students with ADHD seems to promote cognitive and pragmatic gains.
\end{abstract}

Keywords: English Language Teaching. Inclusive Education. ADHD.

\section{Introdução}

Por uma natureza neurobiológica se entende que o Transtorno de Déficit de Atenção e Hiperatividade (doravante TDAH) é diagnosticado quando o aluno apresenta, de forma geral, dificuldades de atenção, de se manter parado (agitação motora), portanto se distrai facilmente. A síndrome foi alvo de várias pesquisas ao longo dos anos, sobretudo, nas áreas de saúde e educação. No entanto, quando o contexto envolve o ensino de línguas, mais especificamente, a língua inglesa (LI), a literatura se apresenta expressivamente escassa, conforme se evidencia ao longo deste escrito.

Nesse viés, entende-se a relevância de se investigar a temática, envolvendo as chances do ensino de LI a alunos com TDAH. Além de uma possível expansão na literatura desse campo, este estudo pode potencialmente promover reflexões e instigar ações futuras para políticas públicas/educacionais, já que, como se sabe, não há políticas específicas para pessoas com TDAH no Brasil atualmente. A legislação pátria a esse respeito, a Política Nacional de Educação Especial na Perspectiva da Educação Inclusiva (BRASIL, 2008) não inclui o TDAH como elemento da educação especial.

Além da justificativa de cunho científico apresentada no parágrafo anterior, acrescenta-se o interesse dos autores no trabalho com a educação especial. Neste artigo se verifica uma oportunidade não só para pesquisar a temática, mas também como prática reflexiva, uma vez que os autores são agentes do contexto educacional, que frequentemente experenciam o TDAH em suas múltiplas faces. Por meio de conversas informais com pedagogos e professores das escolas participantes foi possível constatar que estes nunca participaram de uma pesquisa cujo foco fosse a temática do 
TDAH, portanto tal escassez (como uma problemática de pesquisa) solidificou ainda mais o vislumbre para a condução deste estudo.

Diante do exposto, a justificativa para a realização desta pesquisa recai na escassez de estudos empíricos na literatura, especialmente, na Educação Básica, mais especificamente o Ensino Fundamental.

Este é um estudo de caso, de natureza qualitativa, uma vez que o objetivo foi investigar a realidade e as possibilidades em relação ao ensino de inglês para alunos com TDAH no município de Andirá, no Norte do Paraná. O objetivo específico compreende: descrever e explicar estratégias/ métodos na pedagogia de inglês para alunos com TDAH no município citado.

Alinhadas aos objetivos, as perguntas de pesquisa propostas foram: que desafios, se algum, os professores enfrentam ao ensinar inglês a alunos com TDAH no contexto investigado?; e que estratégias de ensino são empregadas para o ensino de inglês a alunos com TDAH?

\section{Material e Métodos}

Esta pesquisa se embasa em uma natureza qualitativa e diz respeito a um estudo de caso, com foco no ensino de inglês para alunos com TDAH no Ensino Fundamental. Envolve duas professoras de duas escolas estaduais da cidade de Andirá no Estado do Paraná. Nesse sentido, os dados advêm de observação de seis aulas (três em cada instituição participante), materializadas por meio de diários de campo e entrevistas semiestruturadas, gravadas em áudio, com as duas professoras regentes (uma de cada escola). O Quadro 1 sintetiza algumas informações concernentes ao contexto deste estudo.

Quadro 1 - Contexto de Pesquisa

\begin{tabular}{|c|c|c|c|}
\hline Escola & Turma & Docente & Geração de dados \\
\hline $\begin{array}{c}\text { Escola A } \\
(798 \text { alunos })\end{array}$ & $\begin{array}{c}7^{\circ} \text { ano } \\
(12 \text { alunos })\end{array}$ & $\begin{array}{c}\text { Maria } \\
\text { (pseudônimo) }\end{array}$ & $\begin{array}{c}\text { Observação de 3 } \\
\text { aulas de língua } \\
\text { inglesa }\end{array}$ \\
\hline Escola B & $\begin{array}{c}8^{\circ} \text { ano } \\
(10 \text { alunos })\end{array}$ & $\begin{array}{c}\text { Bernadete } \\
\text { (nome real })\end{array}$ & $\begin{array}{c}\text { Observação de 3 } \\
\text { aulas de língua } \\
\text { inglesa }\end{array}$ \\
\hline
\end{tabular}

Fonte: dados da pesquisa..

A primeira turma observada foi um $7^{\circ}$ ano da Escola $\mathrm{A}^{1}$, no período vespertino, durante o mês de agosto de 2018, em três encontros. A instituição possui 798 alunos somados os três períodos de aula e duas professoras de língua inglesa. Como já dito, foram observadas três aulas de língua inglesa ministradas pela professora Maria (pseudônimo), que é formada nos cursos de Letras/Inglês e Pedagogia e com Especialização em Sociologia, Educação Especial e Literatura Infantil. A professora em questão leciona há sete anos, trabalha em quatro escolas e leciona para pelo menos três alunos com algum transtorno (diagnosticado).

A segunda etapa de observação aconteceu na Escola B sob a regência da professora Bernadete dos Santos Meletto (nome real $^{2}$ ), resultando em três encontros. A escola conta com 862 alunos e três professoras de Língua Inglesa. A turma observada foi um $8^{\circ}$ ano do período vespertino durante o mês de setembro de 2018. Bernadete é formada em Ciências Biológicas, e possui especialização em Gestão Escolar: Administração, Supervisão e Orientação Educacional e Educação Especial Inclusiva. Ela leciona há 24 anos e trabalha em apenas uma escola, tendo 10 alunos ao todo, dos quais seis têm algum transtorno.

As instituições escolhidas para a pesquisa estão localizadas em partes diferentes da cidade, uma no centro e a outra na periferia. A escolha das professoras ocorreu por indicação da equipe pedagógica das duas instituições, sendo elas as únicas professoras de língua inglesa que atendiam alunos com TDAH e que se dispuseram a participar voluntariamente da pesquisa.

Ademais, para a geração de dados, foram aplicados um questionário e uma entrevista semiestruturada, gravada em áudio. O Quadro 2 ilustra as ações tomadas a propósito da geração de dados.

Quadro 2 - Geração de Dados

\begin{tabular}{|c|c|c|c|c|}
\hline Escola & Observações & Questionário & Entrevistas & $\begin{array}{c}\text { Carga } \\
\text { Horária }\end{array}$ \\
\hline Escola & $\begin{array}{c}22 / 08 / 2018 \\
22 / 08 / 2018 \\
\text { "A" }\end{array}$ & $13 / 09 / 2018$ & $05 / 09 / 2018$ & 3 horas \\
\hline $05 / 09 / 2018$ & & & \\
\hline Escola & $\begin{array}{c}18 / 09 / 2018 \\
27 / 09 / 2018 \\
\text { "B" }\end{array}$ & $13 / 09 / 2018$ & $18 / 09 / 2018$ & 3 horas \\
\hline
\end{tabular}

Fonte: dados da pesquisa.

As observações de aulas na escola A aconteceram nos dias 22/08/2018 e 05/09/2018, totalizando três horas de aulas observadas. O questionário foi aplicado no dia 13/09/2018 e a entrevista foi realizada no dia 05/09/2018. Em relação à escola $\mathrm{B}$, as observações ocorreram nos dias 18/09/2018 e 27/09/2018, com três horas de aulas observadas, o questionário foi aplicado no dia 13/09/2018 e a entrevista foi gravada no dia 18/09/2018. Os dados foram transcritos e as linhas enumeradas para facilitar a ilustração da análise.

Por fim, como uma forma de assegurar os direitos dos participantes da pesquisa e garantir uma ação ética na condução do estudo, esta pesquisa foi submetida e aprovada pelo Comitê de Ética (CAAE: 92742218.1.0000.8123) da Universidade Estadual do Norte do Paraná. Os professores envolvidos assinaram um Termo de Consentimento Livre e Esclarecido (TCLE) atestando ciência quanto aos processos envolvidos na pesquisa. Nesse sentido, o TCLE produzido está respaldado na Resolução n. 466, 12 de dezembro de 2012 (Conselho Nacional de Saúde), nas Diretrizes Éticas (britânicas) para Pesquisa Educacional (BERA, 2018) e

1 Denominação adotada a fim de se manter o anonimato dos contextos da pesquisa.

2 Opção outorgada ao participante no Termo de Consentimento Livre e Esclarecido. 
o Código de Ética da Associação Americana de Pesquisa Educacional (AERA, 2011).

\section{Resultados e Discussão}

Esta seção está dívida em duas principais partes, a primeira traz uma revisão sistemática de literatura acerca do TDAH no contexto de ensino e aprendizagem de Língua Inglesa (tópicos $3.1,3.2$ e 3.3 ) e a segunda discute os resultados a partir dos dados gerados com as duas professoras regentes (tópico 3.4).

\subsection{Transtorno de Déficit de Atenção e Hiperatividade}

O Transtorno de Déficit de Atenção e Hiperatividade (TDAH), como se conhece hoje tem sido investigado ao longo dos últimos 200 anos, tendo também recebido nomes diferentes nesse período, entre esses: Dano Cerebral Mínimo, Disfunção Cerebral Mínima, Hipercinese e Transtorno da Falta de Atenção (TDA).

Segundo Ornellas e Araújo (2018), o início do século XX foi marcado por uma epidemia de encefalite letárgica, essa doença causava danos físicos e mentais aos pacientes, e várias crianças apresentavam problemas de comportamento após adquirirem a doença, tais problemas eram chamados de distúrbio do comportamento pós-encefalite. Durante algum tempo, as sequelas dessa epidemia foram relacionadas ao transtorno de comportamento.

Nos próximos parágrafos, um panorama a respeito do TDAH, em ordem cronológica, é apresentado.

Crichton (1798) é considerado o primeiro pesquisador a descrever o transtorno. Para o autor, todas as pessoas tinham um certo nível de desatenção, porém algumas apresentavam uma desatenção patológica, o que dificultava o nível de atenção. Ainda, segundo o pesquisador, esse sintoma diminuía com o passar dos anos.

Em seguida, tem-se a obra de Hoffmann (1845), que é formada por nove histórias, e todas trazem personagens com características do TDAH, entre essas: hiperatividade, que se caracteriza pela atividade motora e excessiva falta de autocontrole e desatenção. Os personagens apresentam também o comportamento antissocial que pode ser caracterizado pela rebeldia, impulsividade e até mesmo a agressividade.

Ademais, Still (1902) conduziu uma pesquisa com 43 crianças que apresentavam dificuldades para manter o autocontrole, apresentavam agressividade e eram resistentes à disciplina, esses atributos fizeram com que o autor caracterizasse a doença como um defeito de controle moral.

No ano de 1932, Kramer e Pollnow descreveram o transtorno como uma acentuada inquietação motora, ou seja, segundo os autores, as crianças com a doença hipercinética apresentavam dificuldades em se manterem paradas e concentradas. Diferente dos estudos que haviam sido realizados anteriormente, Kramer e Pollnow (1932) não enfatizavam os comportamentos morais.

Em 1937, o psiquiatra Charles Bradley faz importantes descobertas para o tratamento de crianças com transtorno de comportamento. Bradley descobriu a eficácia da droga benzedrina, que é um estimulante e uma forma racêmica da anfetamina, ao administrá-la em 30 crianças, o psiquiatra percebeu o efeito positivo que a droga possuía, especialmente, no comportamento escolar.

No ano de 1944, o químico italiano Leandro Panizzon sintetizou a droga estimulante Metilfenidato, e no ano de 1954 o medicamento começou a ser comercializado pela companhia farmacêutica em que Panizzon trabalhava sob o nome de Ritalina. Atualmente, esse composto é o mais utilizado para o tratamento de crianças com distúrbios de comportamento.

Couto, Melo Junior e Gomes (2010) apontam que ainda na década de 1940 surgiu um novo conceito designado de "Lesão cerebral mínima”. Essa ideia reforçava que o comportamento hiperativo era causado por lesões no cérebro.

No ano de 1990, o TDAH foi reconhecido como um transtorno que não estava presente somente na infância, mas que poderia se estender até a maioridade.

O Manual Diagnóstico e Estatístico de Transtornos Mentais, DSM5 (APA, 2014) divide o TDAH em três subtipos:

a) Características de desatenção: dificuldade em prestar atenção em tarefas escolares e em tarefas lúdicas, já que está sempre distraído, apresenta dificuldades em relação às tarefas cotidianas, por exemplo: esquecer de fazer a tarefa de casa, dificuldades em organização (o caderno está sempre desorganizado), entre outros.Hiperatividade: a pessoa com o transtorno apresenta dificuldade em ficar parado, por exemplo: fica se mexendo na cadeira, ou fica fazendo movimentos constantes com as mãos ou pés. Frequentemente, interrompe conversas alheias, ou responde a perguntas antes mesmo de essas serem terminadas, tem dificuldade em esperar sua vez e, frequentemente, corre e sobe nas coisas em momentos inapropriados.Impulsividade (tipo combinado): acontece quando os sintomas, tanto de hiperatividade quanto de desatenção, estão presentes por um período de seis meses.

b) $\mathrm{O}$ tratamento recomendado é uma junção de tratamento psicológico, acompanhamento dos pais e professores e medicação.

Uma vez apresentado um cenário do Transtorno de Déficit de Atenção e Hiperatividade, aborda-se na próxima seção uma revisão de literatura no campo de ensino e aprendizagem de língua inglesa para alunos com TDAH.

\subsection{Ensino e aprendizagem para pessoas com TDAH}

O ambiente escolar prova ser um grande desafio para crianças com TDAH, já que elas apresentam dificuldades de concentração. Com isso em mente, Silvestre et al. (2016, p.11) postulam que:

A dificuldade de atenção é muito intensa, a distração vem com muita facilidade: se ele estuda pela manhã, as primeiras horas são mais fáceis para esse aluno trabalhar em sala; com o passar das horas, ele já começa a ficar um pouco agitado. No momento em que esse aluno começar a ficar agitado, o profissional deve criar estratégias para que ele mude o seu foco e faça coisas diferentes para mudar sua rotina.

Ainda, segundo Oliveira e Silva (2016), o professor tem 
um papel muito importante no desenvolvimento escolar dos alunos com TDAH. De acordo com os autores se deve focar nos pontos fortes desses alunos e o estímulo deve ser constante. O uso de estratégias de ensino também deve estar presente, e estas devem respeitar a realidade dos discentes e promover a interação (relacionamento com a turma e professores) e integração (inserção do aluno em sala de aula) destes com o restante da turma.

Para Pereira (2009), há uma série de estratégias que devem ser seguidas pelos professores para que a aprendizagem e integração, em sala de aula, do aluno com TDAH aconteçam de forma satisfatória, entre tais estratégias estão: estabelecer uma rotina clara com os alunos, dividir as atividades em unidades menores, usar reforços visuais e auditivos, definir regras e expectativas (e.g., cartazes, calendários, cronogramas). Complementarmente, Fonseca (2014, p.31) argumenta que:

Segundo a Associação Brasileira do Déficit de Atenção (ABDA), para que um aluno com TDAH possa ser avaliado, é importante atentar para o que mais atrapalha seu desempenho escolar. Em seguida, é fundamental que se saiba avaliar o que o aluno consegue ou não fazer a fim de que não se crie falsas expectativas. Outra dica é recompensar melhorias em seu desempenho escolar (comportamento, trabalhos bem feitos, entre outros) ao invés de esperar por um comportamento exemplar de imediato.

Ainda, segundo Fonseca (2014), tal processo, se adotado pelos professores, tem grande significância na aprendizagem do aluno com TDAH, já que eles têm dificuldades em compreender recompensas dadas em longo prazo.

No contexto escolar (ensino, aprendizagem, avaliação e outros), entende-se que as estratégias discutidas pelos autores devam ser compreendidas como recursos que promovam, efetivamente, a integração/interação do aluno com TDAH, de forma harmoniosa, em sala de aula, sem causar ônus a quaisquer sujeitos envolvidos nesse processo. No entanto, salienta-se que tal processo é, consideravelmente complexo, uma vez que é preciso levar em conta inúmeras variáveis, como infraestrutura escolar (o que envolve material didático e outros recursos didático-pedagógicos), questões psicossociais (tantos dos alunos com e sem TDAH) e, sobretudo, a formação dos professores atuantes em turmas com TDAH. A esse respeito se destaca a necessidade de aperfeiçoamento desses profissionais, que diariamente lidam não só com o TDAH, mas com muitos outros transtornos que influenciam o processo de ensino e aprendizagem como um todo.

\subsection{Pesquisas sobre o TDAH na pedagogia de Língua Inglesa}

A revisão de literatura da pesquisa foi realizada durante o segundo semestre de 2019, com o objetivo de mapear os estudos já existentes sobre o ensino de Língua Inglesa para alunos com Transtorno de Déficit de Atenção e Hiperatividade. Os bancos de dados utilizados foram: Scielo, Google, Google Acadêmico e CAPES. Os termos utilizados foram: "TDAH" e "Ensino de inglês", "TDAH e língua inglesa" e "Ensino para alunos com TDAH". Com essa busca não foram encontrados resultados nas plataformas SciELO e CAPES. Em relação ao Google e Google acadêmico, quatro pesquisas foram obtidas (Quadro 3).

Quadro 3 - Pesquisas sobre o TDAH no ensino de Língua Inglesa

\begin{tabular}{|c|c|c|}
\hline Pesquisa & Foco & Contexto \\
\hline Fonseca (2014) & $\begin{array}{c}\text { Estratégias de ensino para alunos } \\
\text { com TDAH }\end{array}$ & UCM \\
\hline Freitas (2017) & $\begin{array}{c}\text { Estratégias de ensino para alunos } \\
\text { com TDAH }\end{array}$ & UFP \\
\hline Pereira (2009) & $\begin{array}{c}\text { TDAH e o ensino de inglês como } \\
\text { língua estrangeira }\end{array}$ & UCM \\
\hline Martins (2011) & $\begin{array}{c}\text { Métodos e práticas para o ensino } \\
\text { de língua inglesa }\end{array}$ & UCB \\
\hline
\end{tabular}

Fonte: dados da pesquisa.

Fonseca (2014) discorre sobre a grande procura de cursos de Inglês na atualidade. O objetivo da autora foi mostrar o processo de ensino e aprendizagem da Língua Inglesa de um aluno com Déficit de Atenção e Hiperatividade. Para realizar tal pesquisa, Fonseca (2014) observou a atuação dos professores desse curso, fez uma análise das avaliações feitas por esse aluno, e da atuação dos professores e pais do aluno durante o período em que ele esteve no curso de inglês. Ao final do estudo, a autora concluiu que o período em que o participante permaneceu no curso de inglês o ajudou em seu desenvolvimento cognitivo e, também, trouxe melhorias em sua autoestima e socialização.

Freitas (2017) traz dados sobre uma série de observações feitas em uma escola privada de idiomas na Capital da Paraíba. A autora visou mostrar as principais dificuldades de um aluno do curso com TDAH e as estratégias que são utilizadas pelos professores para melhorar o ensino desse aluno. Posteriormente, a autora elenca uma série de estratégias que podem ser utilizadas, a saber: atividades que sejam breves, com grau de dificuldade compatível ao nível cognitivo do aluno, atenção especial do professor para o aluno durante a resolução das atividades, suporte da escola, atividades que chamem a atenção do discente e tarefas que envolvam movimentos com o corpo (atividades que levem o aluno a se movimentar).

Pereira (2009) discorre sobre as dificuldades de se ensinar a Língua Inglesa para alunos com TDAH no Ensino Fundamental I, segundo a autora, além da escassez de materiais e elementos lúdicos para o melhor aproveitamento das aulas, há também a grande quantidade de alunos, o que dificulta a realização de atividades diferenciadas para os alunos com o transtorno.

Martins (2011) traz um panorama sobre o transtorno, citando os sintomas, o diagnóstico, as causas e o tratamento. Posteriormente, a autora discorre sobre como o transtorno pode afetar o desempenho escolar desses alunos e algumas estratégias para melhorar o processo de aprendizagem desses alunos.

Ao se comparar as quatro pesquisas fica evidenciado que 
os dois estudos não empíricos (PEREIRA, 2009; MARTINS, 2011) e um empírico (FREITAS, 2017) corroboram as mesmas dificuldades e estratégias contempladas na literatura sobre TDAH: atividades curtas, não usar o reforço negativo, atividades que façam os alunos se movimentarem, compatíveis com o nível cognitivo do aluno, e outras similares.

No que tange a Fonseca (2014), acolhe-se a importância da língua estrangeira para o repertório intelectual do aluno (o que também inclui ganhos de ordem sociointeracional). No entanto, entende-se que há a necessidade de uma investigação mais aprofundada, o que inclui: estratégias específicas da pedagogia de Língua Inglesa ao aluno com TDAH, questões sociais e afetivas com a língua entre outras variáveis.

\subsection{Análise de dados}

À luz da análise qualitativa de dados, mais especificamente com o foco no conteúdo ${ }^{1}$ (BARDIN, 2016), esta seção traz as percepções dos professores entrevistados a respeito de seus alunos com TDAH. Basicamente, os dados derivam de suas grandes dimensões analíticas: Interação e Método e subordinadas a essas dimensões são induzidas algumas categorias e subcategorias, sendo as categorias e sublinhado as subcategorias, como ilustrado a seguir:

Quadro 4 - Classificação Analítica

\begin{tabular}{|c|c|}
\hline Inte & Método \\
\hline $\begin{array}{c}\text { Frequência Ganho } \\
\text { / I I Baixa Pragmático Cognitivo } \\
\end{array}$ & $\begin{array}{c}\text { Virtual Assistemático Lacuna } \\
\text { / । I I } \\
\text { Escrita Oralidade Estrutura }\end{array}$ \\
\hline
\end{tabular}

Fonte: os autores.

Nos próximos parágrafos se detalha cada classificação analítica com seus respectivos excertos.

\subsubsection{Interação}

A primeira classificação acerca da interação dos alunos em sala de aula, o que por sua vez envolve a frequência da interação, aos ganhos obtidos por meio de tal interação.

Quadro 5 - Interação

\begin{tabular}{|c|c|c|c|}
\hline \multicolumn{2}{|c|}{ Frequência } & \multicolumn{2}{c|}{ Ganho } \\
\hline$\underline{\text { Alta }}$ & $\underline{\text { Baixa }}$ & $\underline{\text { Pragmático }}$ & $\underline{\text { Cognitivo }}$ \\
\hline $\begin{array}{c}\text { Maria e } \\
\text { Bernadete }\end{array}$ & Bernadete & Bernadete & $\begin{array}{c}\text { Maria e } \\
\text { Bernadete }\end{array}$ \\
\hline
\end{tabular}

Fonte: dados da pesquisa.

A frequência diz respeito à convivência dos alunos (com TDAH), em sala de aula, como eles se relacionam com os professores e com o restante da turma.

Com o aluno da escola A (da professora Maria) se nota que a interação deste, em sala de aula, é alta, ele tem uma boa comunicação com os colegas, e mesmo sendo muito agitado, é bastante participativo nas atividades, como se pode evidenciar no trecho da entrevista e das observações de aula respectivamente:
Ele se comunica normalmente com os outros alunos, posso dizer que ele tem mais facilidade de aprender a minha matéria do que os outros (L.157-158, Maria).

Ele conversa muito desde o inicio da aula, caminha pela sala e tira a atenção do restante da turma (L. 5-6, Pesquisadores). $\mathrm{O}$ aluno com TDAH está sentado e conversando com um colega (L. 41-42, Pesquisadores).

O uso do advérbio 'normalmente' empregado no primeiro excerto sinaliza que a interação, portanto, parece sustentar a classificação analítica. Ademais, o comportamento relatado no segundo excerto ratifica as características da criança com TDAH, que já foram discorridas neste artigo (APA, 2014).

Em relação ao aluno da Escola B (da professora Bernadete), a interação é mista, já que ele foi observado em dois contextos diferentes. Primeiramente, no período da manhã, durante a aula de reforço junto com colegas que apresentam o mesmo transtorno que ele e o segundo contexto foi no período de aula regular, no período vespertino.

Durante a aula de reforço, a interação do aluno em sala é alta, ele se comunica normalmente com os colegas, como confirma Bernadete:

Ele passa toda a aula fazendo essa atividade, e se comunica bastante com dois dos colegas e com a professora (L. 52-53, Pesquisadores).

Quando o contexto de observação é o horário regular de aula, a interação do aluno é baixa, ele não tem contato com o restante da turma e, na maior parte do tempo, ele se comunica apenas com a professora auxiliar. Sobre a interação do referido aluno, a professora ressalta:

Então, na realidade, em relação ao aluno, que tem também Asperger, né, ele é um autista, é, a interação dele com os outros é bem pouca, ele é um menino que gosta mais de ficar isolado, ele não gosta de participar de atividades em grupo (L. 84-86, Bernadete).

O excerto parece sinalizar que a falta de interação do aluno em horário regular de aula não é mediada pela professora. Em outras palavras, a baixa interação se coaduna com a não integração do discente com TDAH, que tem sua socialização fragilizada. Além disso, pode-se evidenciar que a não integração é associada à ausência de variação de procedimentos didáticos pela docente (PEREIRA, 2009; FREITAS, 2017).

Em relação aos ganhos do aluno da escola A, pode-se pontuar um cunho cognitivo, que é aquele que diz respeito ao processo de aprendizagem e socialização do aluno:

É muito importante a socialização desse aluno pois ele se sente importante, igual aos outros alunos na sala de aula (L. 164-165, Maria).

No que diz respeito aos ganhos do aluno da escola B, compreende-se que são pragmáticos, ou seja, aqueles relacionados à vida cotidiana:

Trabalhando na escola, né, no ensino regular, trabalhando

1 De forma geral, a Análise de Conteúdo (AC) prevê a redução dos dados, por meio de categorizações (categorias e dimensões analíticas). 
com a inclusão, eu percebo que para eles é muito importante, porque eu também, como professora de apoio especializado, eu também ensino coisas da vida cotidiana para ele, né, e, ao mesmo tempo ele também aprende a conviver com os problemas do dia a dia, ele consegue enfrentar os desafios que surgem no dia a dia (L. 116-119, Bernadete).

Adicionalmente, pode-se demonstrar ganho de fundo cognitivo na escola B (relacionado a fatores de aprendizagem):

Além dessa socialização, de conviver com pessoas "normais", eu acho que ele também tem a oportunidade de aprender agora com essa oportunidade que o governo deu, de um professor de apoio para ajudar ele especificamente, então eu acho que sim, que está sendo muito importante a questão da inclusão, dessa inserção do aluno, é, no ensino regular (L. 124-128, BERNADETE).

Com base na literatura apresentada, na seção teórica, a interação de alunos com TDAH, sobretudo, nas aulas de línguas (foco deste estudo), potencialmente, essa traz ganhos cognitivos (FONSECA, 2014). Nesse sentido, este estudo não apenas corrobora tal premissa, mas também inclui ganhos de natureza pragmática.

\subsubsection{Método}

Nesta subseção se aborda a questão do método para a pedagogia de Língua Inglesa para alunos com TDAH. O quadro 6 sintetiza a sistematização sobre o método, o que, por sua vez, se apresenta em nível virtual, assistemático (em que a escrita e a estrutura predominam) e ainda inclui lacunas.

Quadro 6 - Método

\begin{tabular}{|c|c|c|c|c|}
\hline Virtual & \multicolumn{3}{|c|}{ Assistemático } & Lacuna \\
\hline \multirow{2}{*}{$\begin{array}{c}\text { Maria e } \\
\text { Bernadete }\end{array}$} & Escrita & $\underline{\text { Oralidade }}$ & Estrutura & \multirow{2}{*}{$\begin{array}{c}\text { Maria e } \\
\text { Bernadete }\end{array}$} \\
\hline & $\begin{array}{c}\text { Maria e } \\
\text { Bernadete }\end{array}$ & Bernadete & $\begin{array}{c}\text { Maria e } \\
\text { Bernadete }\end{array}$ & \\
\hline
\end{tabular}

Em relação a um método específico para alunos com TDAH, este se apresenta em um nível virtual, já que mesmo sendo pautado pelas professoras, esse não acontece de fato (é apenas idealizado). Isso é realidade tanto na escola $\mathrm{A}$ (professora Maria) quanto na escola B (professora Bernadete):

Jogos interativos com imagens, algo mais lúdico, de fácil entendimento para que ele entenda (L. 168-169, Maria).

É, na realidade, eu acho que em relação a disciplina de inglês, né, se tivesse esse ensino do inglês desde a educação infantil, ensino fundamental anos iniciais, já tivesse o ensino de inglês, eu acho que quanto menor, mais facilidade a criança tem de aprender, a gente tira a ideia por, andar de bicicleta, se uma criança aprende a andar de bicicleta ela tem muito mais facilidade de aprender do que um adulto, e tudo na vida é assim, a gente aprende com muito mais facilidade quando a gente ainda é pequeno, então eu acho que se ensinasse inglês já desde pequenininho a criança teria muito mais facilidade de aprender, porque ela já vai aprender a ser alfabetizado em mais de uma língua, né, então isso facilitaria (L. 140-148, Bernadete).

Nesse sentido, parece não haver uma sistematização do método na escola A (assistemático), ou seja, o aluno com TDAH realiza as mesmas atividades do restante da turma, sem exercícios diferenciados, conforme a literatura prescreve:

A professora começa a passar um texto no quadro negro, e pede para que os alunos o copiem (L. 31-37, PESQUISADORES).

Durante esse tempo, a professora continua passando os exemplos e exercícios no quadro, todos os alunos continuam conversando, porém, a bagunça está menor (L. 10-13, PESQUISADORES).

A falta de sistematização pode ser verificada, uma vez que todos os alunos da escola $\mathrm{A}$ recebem as mesmas atividades, inclusive o aluno com TDAH, ou seja, existe uma homogeneização do método. Desse modo, parece acertado asseverar que a falta de sistematização de um método para alunos com TDAH pode estar intimamente relacionada à baixa integração desse segmento de alunos.

O método assistemático também é realidade da outra instituição pesquisada, conforme ilustrado no excerto:

Olha, na realidade não, eu não utilizo uma estratégia específica né, eu sigo as estratégias do professor da turma, porque ele ensina, por exemplo, através de um modelo a atividade, por exemplo, e vai dar uma atividade, então ele faz um modelo, e a gente segue o modelo e faz os outros exercícios, então a gente não tem, assim, uma estratégia, a gente segue o que o professor ensina, também considerando que o aluno tem bastante facilidade nessa disciplina (L.77-82, Bernadete).

O excerto acima sugere que a professora não utiliza estratégias diferenciadas no ensino do aluno, visto que o aluno tem muita facilidade na disciplina, o que parece eliminar a necessidade do uso de estratégias específicas.

Ainda, percebe-se que o método de ensino de Língua Inglesa em geral é predominantemente pautado na escrita e estrutura linguística nas duas escolas:

A professora, então, sem conversar com os alunos passa exercícios do livro didático no quadro negro. Momentos depois, os 21 alunos que estão em sala começam a copiar o que está no quadro (L.1-4, Pesquisadores).

$\mathrm{O}$ aluno com TDAH está sentado na primeira mesa da fila copiando a matéria do quadro, e a professora auxiliar está sentada ao lado dele, o restante da turma também está copiando as atividades (L. 57-59, Pesquiadores).

As atividades dadas pela professora são sobre os adjetivos possessivos His e Her, são todos exercícios de completar os espaços em branco (L.11-13, Pesquisadores).

No segundo encontro, a professora está dando aula de gramática, sobre How many e How much (L. 56-57, Pesquisadores)

$\mathrm{O}$ primeiro e segundo excerto dizem respeito à escrita e correspondem, respectivamente, às escolas A e B. Já o terceiro e quarto também respectivos para as escolas A e $\mathrm{B}$ estão relacionados à estrutura linguística. Esses dados sinalizam um ensino de línguas pautado por métodos/ abordagens tradicionais, que priorizam a língua escrita, bem como a estrutura. Com isso em mente, é importante destacar que tais atributos se distanciam muito das tendências contemporâneas para o ensino de línguas, que focam em aspectos sociointeracionais, críticos entre outros (PARANÁ, 2008).

Os dados apontam que apenas a escola B aborda a 
oralidade nas aulas de Língua Inglesa:

A professora regente explica para a turma como fazer a resolução dos exercícios, e depois de alguns minutos, ela começa a correção junto com a turma, ela faz as perguntas e os alunos têm que completar oralmente (L. 60-63, PESQUISADORES).

Por fim, as professoras investigadas confidenciam uma lacuna em relação às questões metodológicas:

Acho que pelo menos uma vez por ano, o governo mandasse uma pessoa capacitada para nos ensinar como trabalhar com esse aluno, pois alguns, dependendo do transtorno tem uma professora habilitada para trabalhar com ele (L. 171-173, Maria).

O desafio maior é eu conseguir ensinar, porque eu tenho bastante dificuldade no inglês, então, na verdade eu 'tô' aprendendo junto com ele, né, eu 'tô' aprendendo inglês junto com ele, às vezes ele mesmo me corrige, porque ele tem mais facilidade, ele já conhece, né, ele teve essa oportunidade de os pai terem morado nos Estados Unidos, então ele sabe bastante, até mais do que eu, então é um desafio (L. 94-98, Bernadete).

Nesse sentido, os dados evidenciam uma carência/lacuna na formação de professores, com vistas ao atendimento de alunos com necessidades especiais. Tal resultado pode estar associado com a escassez de pesquisas empíricas nessa temática, conforme se discorre na revisão de literatura. Ademais, entende-se que tal lacuna reflete a ausência de políticas públicas específicas para indivíduos com TDAH (BRASIL, 2008). Além disso, a professora da escola B sinaliza uma dificuldade de ordem cognitiva, o que, ao ver da pesquisa, também se coaduna ao âmbito de formação de professores.

Durante as observações de aulas foi possível perceber que os dois alunos apresentavam várias das características atribuídas a pessoas com o TDAH, como a desatenção, e a dificuldade em se manter parados e concentrados nas atividades, entre outras (APA, 2014). As observações de aulas também possibilitaram acompanhar as atitudes dos professores das respectivas escolas, e constatar se eles utilizavam estratégias que poderiam, de alguma forma, melhorar o desempenho dos alunos com TDAH em sala de aula. Assim, tais questionamentos seguem detalhados nos próximos parágrafos.

Nesse sentido, são retomadas as perguntas de pesquisa e os objetivos que foram expostos no início deste estudo:

a) que desafios, se algum, os professores enfrentam ao ensinar inglês a alunos com TDAH no contexto investigado? Segundo a professora Maria, os desafios enfrentados podem variar de acordo com o nível do transtorno do aluno. Com as observações de aula, foi possível notar que o aluno não apresenta dificuldades na Língua Inglesa e, de acordo com a análise, o maior desafio enfrentado pela professora é manter o aluno focado nas atividades, já que o nível de hiperatividade dele é muito alto. Em relação à professora da escola B, o maior desafio encontrado está na própria Língua Inglesa, já que ela não possui formação na área. Assim, há processo de aprendizagem mútuo entre ela e o aluno.

b) que estratégias de ensino são empregadas para o ensino de inglês a alunos com TDAH? Freitas (2017) traz uma série de estratégias que podem ser utilizadas com alunos com TDAH para que o desempenho deles em sala possa ser satisfatório, tais como: exercícios curtos, atividades que façam os alunos se movimentarem, entre outras. Nesse sentido, foi possível observar que nas duas escolas não são utilizadas estratégias específicas para o ensino de LI aos alunos com TDAH, não há uma sistematização e eles fazem as mesmas atividades que o restante da turma (ensino homogêneo). Portanto, o método é virtual e assistemático e é majoritariamente embasado em métodos cujos focos são na escrita e estrutura da língua.

Foi possível também associar a falta de sistematização à escassez de materiais didáticos (PEREIRA, 2009), que auxiliem os professores no ensino de alunos com TDAH. Levando isso em consideração foi possível notar que a precariedade de materiais didáticos nessa temática é uma realidade nas duas escolas investigadas. Além disso, a escassez de pesquisas empíricas e ausência de políticas públicas dificultam, significativamente, a pedagogia de língua estrangeira a indivíduos com o transtorno.

Não obstante, vale ressaltar que no caso dos alunos observados, essa falta de sistematização parece não interferir na aprendizagem, já que o desempenho deles é satisfatório na disciplina de Língua Inglesa (como apontam as professoras).

Em complemento se traz a seguir discussão para os objetivos (geral e específico) desta pesquisa:

a) descrever e explicar estratégias/métodos na pedagogia de inglês para alunos com TDAH no município de Andirá, no Norte paranaense: foi possível observar que o ensino para esses alunos é permeado por uma falta de sistematização e até mesmo uma falta de materiais que auxiliem os professores e alunos. Além disso, lacunas na formação (inicial e continuada) de professores também são variáveis que interferem no processo.

\section{Conclusão}

Para concluir, espera-se que esta pesquisa possa auxiliar pesquisadores e/ou professores que se interessem pela temática abordada, sobretudo no contexto da Educação Básica de escolas públicas, já que, como citado anteriormente, a literatura é expressivamente escassa. Assim, com base nos resultados obtidos nesta pesquisa é possível que professores e pesquisadores possam observar as lacunas existentes no ensino de Língua Inglesa para alunos com TDAH, podendo assim buscar melhorias, para que essas lacunas sejam minimizadas. Nesse sentido, esta pesquisa abre espaço para futuras discussões e pesquisas acerca do ensino de Língua Inglesa para alunos com TDAH e, também, com outras necessidades.

Além disso, os resultados deste estudo evidenciam uma formação de professores lacunosa, quando se trata de ensino e aprendizagem de línguas a alunos com necessidades especiais. Portanto, além de contribuições teórico-metodológicas, esta pesquisa pode abrir margem de uma discussão para futuros encaminhamentos para a formação de professores de línguas, seja por meio de políticas educacionais, pesquisa, extensão e 
outros segmentos.

\section{Referências}

AERA - American Educational Research Association. Code of ethics. 2011. Disponível em: <http://c.ymcdn.com/sites/www. weraonline.org/resource/resmgr/a_general/ aera.pdf $>$ Acesso em 23 maio 2020.

APA - American Psychiatric Association. Manual diagnóstico e estatístico de transtornos mentais (DSM-IV-TR). Porto Alegre: Artes Médicas, 2014.

BARDIN, Laurence. Análise de conteúdo: edição revista e ampliada. São Paulo: Edições 70, 2016.

BERA. Ethical Guidelines for Educational Research. 2018. Disponível em <http://www.bera.ac.uk/>. Acesso em: 5 maio 2020.

BRASIL. Ministério da Educação. Política Nacional de Educação Especial na Perspectiva da Educação Inclusiva. Portaria no 555/2007, prorrogada pela Portaria no 948/2007. Brasília: MEC, 2008.

BRADLEY, C. The behavior of children receiving benzedrine. Am. J. Psychiatr., v.94, p.577-585, 1937 . doi: https://doi. org/10.1176/ajp.94.3.577

COUTO, T.S.; MELO-JUNIOR, M.R.; GOMES, C.R. Aspectos neurobiológicos do transtorno do déficit de atenção e hiperatividade (TDAH): uma revisão. Ciênc. Cognição, v.15, n. 1, p.1-11, 2010.

CRICHTON, A. An inquiry into the nature and origin of mental derangement: comprehending a concise system of the physiology and pathology of the human mind and the history of the passions and their effects. J. Atten. Disord., v.12, p.200-204, 1798.

FONSECA, A.M. A criança TDAH e o ensino de inglês. Rio de Janeiro: Universidade Candido Mendes, 2014.

FREITAS, G.M. Estratégias de ensino da língua inglesa para alunos com transtorno do déficit de atenção com hiperatividade. João Pessoa: Universidade Federal da Paraíba, João Pessoa, 2017.

HOFFMANN, H. Struwwelpeter in English translation. Nova
York: Dover, 1845.

KRAMER, F.; POLLNOW, H. Sobre um distúrbio hipercinético. Monatsschr Psychiatneurol, 1932.

MARTINS, S.M.L. Métodos e práticas de ensino de língua inglesa para alunos com Déficit de Atenção e Hiperatividade. Brasília: Universidade católica de Brasília, 2011.

OLIVEIRA, G.M.; SILVA, R.T. Inclusão e alfabetização da criança com TDAH: um desafio. Rev. Cient. Multidisc. Núcleo do Conhecimento, v.7, n.2, p.91-108. 2016.

OLIVEIRA, R.M.N. O professor e a inclusão do aluno com déficit de atenção e hiperatividade. Jacarezinho: Universidade Estadual do Norte do Paraná, 2014.

ORNELLAS, S.M.B.; ARAÚJO, D.C. Transtorno de déficit de atenção e hiperatividade (TDAH): diagnostico e ambiente escolar. Três Lagoas: Faculdades Integradas de Três Lagoas, Três Lagoas, 2018.

PARANÁ. Secretaria de Educação e Espoetes. Diretrizes Curriculares Estaduais- Lingua Estrangeira. Curitiba: SEED, 2008.

PEREIRA, A.S.P. TDAH e o ensino de inglês como língua estrangeira: o desafio de conviver com alunos com déficit de atenção e hiperatividade numa sala de inglês no ensino fundamental I. Rio de Janerio: Universidade Candido Mendes, 2009.

SENEFONTE, F.H.R. Inglês Informal: aprendizagem, ensino e formação de professores. Londrina: Universidade Estadual de Londrina, 2018.

SILVESTRE, A. et al. Família e a escola na aprendizagem da criança com TDAH: a necessidade de uma parceria ativa e produtiva. Belo Horizonte: Universidade Católica, 2016.

STILL, G. Someabnormalpsychicalconditionsinchildren-Lecture I. Lancet, p.1008-1012, 1902 . doi: 10.1177/1087054706288114 